\title{
Aspects of the psychological perception of the modern urban environment
}

\author{
Darya Belinskaya ${ }^{1^{*}}$ \\ ${ }^{1}$ Moscow State University of Civil Engineering, Moscow, Russia
}

\begin{abstract}
The results of the study emphasize the importance of a "comfortable city" for a modern resident of a megalopolis, a city. The colors around us form our mood and psychological health. The environment surrounding us forms an individual attitude towards ourselves and our future. The environment surrounding us has the most direct impact on the psyche of the individual, forming his attitude towards everything that surrounds him.
\end{abstract}

\section{Introduction}

Nowadays, modern Russian cities are developing serious competition for the improvement and comfortable living of not only visitors to their cities, but also their residents. Recently, modern Russian cities suffered from a complete lack of individuality, poor infrastructure, and a pronounced depressive mood among the townspeople. In Russian cities, there were no parks, cozy playgrounds, and also public places for recreation for citizens.

"A city for a comfortable life", according to A. Kaplan [1], should take into account the needs of a person living in urban space. After his research, the following classification was proposed:

- "physiological needs" - temperature, light, air, noise, etc.;

- "need for security" - when designing the spatial organization of the urban environment, it is necessary to take into account the conditions of the "territorial behavior of the resident", any person should have the possibility of privacy, the social environment should correspond to his claims;

- "social needs" - there should be a place for convenient communication between citizens in all public facilities of the urban environment;

- "ego need" - it is important for a city resident to have an environment created by the feeling of having control;

- "need for self-realization" - the ability to identify oneself with the environment and self-development.

By analyzing various research approaches, determining the stress factors of the urban environment, it can be completely objectively stated that "A city for a comfortable life" should meet a number of parameters:

\footnotetext{
* Corresponding author: doptaganka@yandex.ru
} 
- "visual diversity of objects" - the visual environment can cause both positive and negative emotions leading to discomfort. The modern city makes a person spend most of his time in the artificial visual environment created by man himself, and it is possible to emphasize that in large cities, the subject is continuously in a landscape created by him. [2]

- "predictability" - determinism expressed in the system of interaction of a city resident with the environment, is one of the main issues of modern psychology. Asmolov A. G [3], Steinbach H. E. substantiated with their studies the influence of the urban environment on the emotional reaction that, in turn, forms the level of tolerance of a resident of the urban environment. Tolerance implies intellectual flexibility; creativity can be one of the components of tolerance. Therefore, creativity is considered as one of the factors determining the perception of the urban environment; [7]

- "social potential" - the project activity of the builder should take into account not only the functional but also the social basis, taking into account the basic physiological and psychological characteristics of a person living in an urban environment;

- "aesthetics - an architect must have knowledge of the psychology of age-related characteristics of a person. Using this knowledge, he should take into account the needs of people in the construction and design of the urban environment." V. Lazareva [6, p.21] writes the following in her works: "The criterion for the aesthetic quality of a work of urban planning and architecture is the sensual and emotional perception of man. Only in relation to man, his needs and perception does the harmonic unity of the whole make sense, which is the subject of architectural and spatial composition";

- "safety" - in order to feel safe, the city resident needs not only to get used to the conditions of the city environment, but also to be sure of a positive outcome in case of "emergencies" in the city. The curriculum proposed A.V. Anisimov can be one of the ways to solve such problems. It forms the "architectural education". This work must be carried out, as he considers, first of all, with workers in related professions, for example, firefighters, doctors, and officials. In his works, A.V. Anisimov also [1] insists on teaching the basics of architecture in schools, secondary schools in order to formulate cultural values of architectural heritage;

Studies of mental phenomena that consider a person in constant interaction with the living space surrounding him and the environment can be found in the works of Yu.G. Abramova, H.E. Stein, V.I. Elensky, A.V. Stepanov, S.A. Khasieva.

In his works, H.E. Steinbach describes an analysis of the influence of the quality of an artificial or natural environment as a factor in the creation of cognitive structures of a person and the characteristics of his character in the process of ontogenesis. The popular psychosemantic method proposed by C. Osgood is used as one technique for studying social expectations and social stereotypes of respondents living in an urban environment. N.M. Lebedeva used this method to study the adaptation of the person to a different urban environment. Studies were conducted by O.A. Brown and N.V. Werner [3] in Kemerovo using the method of semantic differential, the purpose of which was to study the "pragmatic meanings". Obtained results showed that the received amount of emotionally positive information exceeds the received amount of negative information. The characteristics of the respondents can be categorized as "assessment" - beautiful, bright, colorful, gray, etc., "social environment" - positive, trustful, thoughtful people, hurrying people, homeless people, etc., "opportunities for self-realization" - a developing cultural, scientific center, "environmental situation"- dirty, gassed. The object and spatial environment acquires the aesthetic meaning of its existence from a resident of the urban environment. Therefore, a new definition of "architectural quality of the environment" appears, which determines the degree of emotional impact on a person. [2]. To resolve stressful situations and improve the urban environment, studies have been and still being conducted by scientists for over 50 years. 
The problem of determining the influence of the city on the mental state and consciousness of a resident of the urban environment, the impact of the spatial and objective properties of the environment and the discrepancy between the anthropogenic (urban) spatial environment and human nature remain insufficiently studied.

\section{An empirical study of features of the urban environment perception}

Our study made it possible to illustrate the psychological factors that determine the perception of the urban environment. We tried to analyze the influence of the urban environment on the mental state of a person, identifying the main incentives, examined tolerance and creativity as the main factors influencing the level of human perception of the urban environment.

To conduct an empirical study, the following research methods were selected: content analysis, psychological techniques, and an author's questionnaire. To obtain objective research results, we selected psychological tests: "Creativity" (N. V. Vishnyakova) and "M1 Tolerance" (L.V. Menshikov, O.S. Shemelin), projective methodology "unfinished sentence" Topic: "City", Semantic differential, "Tolerance" [5], psychological methodology "Measurement of artistic and aesthetic needs" by V. S. Avanesov. Processing of the obtained data was carried out in Microsoft Excel and Statistica 6.0, criteria were used: Mann-Whitney U-test, Spearman's rank correlation coefficient $r$, Pearson's $\chi 2$ test.

\section{Empirical base of research}

The study involved students of 3-4 years of undergraduate of the Perm Polytechnic University. The total sample was 255 respondents.

\section{The study was conducted in two stages: pilot and main}

When conducting a pilot study, the respondents were students of the Perm National Research Polytechnic University. The respondents in the main study were students of 3-4 years: "Faculty of Electrical Engineering", "Faculty of Humanities" and "Faculty of Civil Engineering" (195 students) aged 19-21, mixed gender.

\section{Results}

\subsection{The results of the pilot study}

After conducting research on the external appearance of the city of Perm, students endowed the city with the following characteristics, which can be called basic: dirty, big, beautiful, noisy, fussy, developing, crowded, young. When students were tasked with proposing better living conditions in their city, $39 \%$ of respondents suggested reducing the number of vehicles on the streets of Perm. $68 \%$ of students propose building a light metro.

Answering a question about changes in the external appearance of the city of Perm, the respondents had to not only evaluate the current state of their city, but also give their recommendations for improving the urban environment: plant greenery, clean and tidy up, remove outdoor advertising, and install lighting. The resulting assessment "Perm is my city" is formed from positive and negative factors. For example, negative external factors were called:

- a lot of advertising;

- messy courtyards and streets;

- dirt in the yards; 


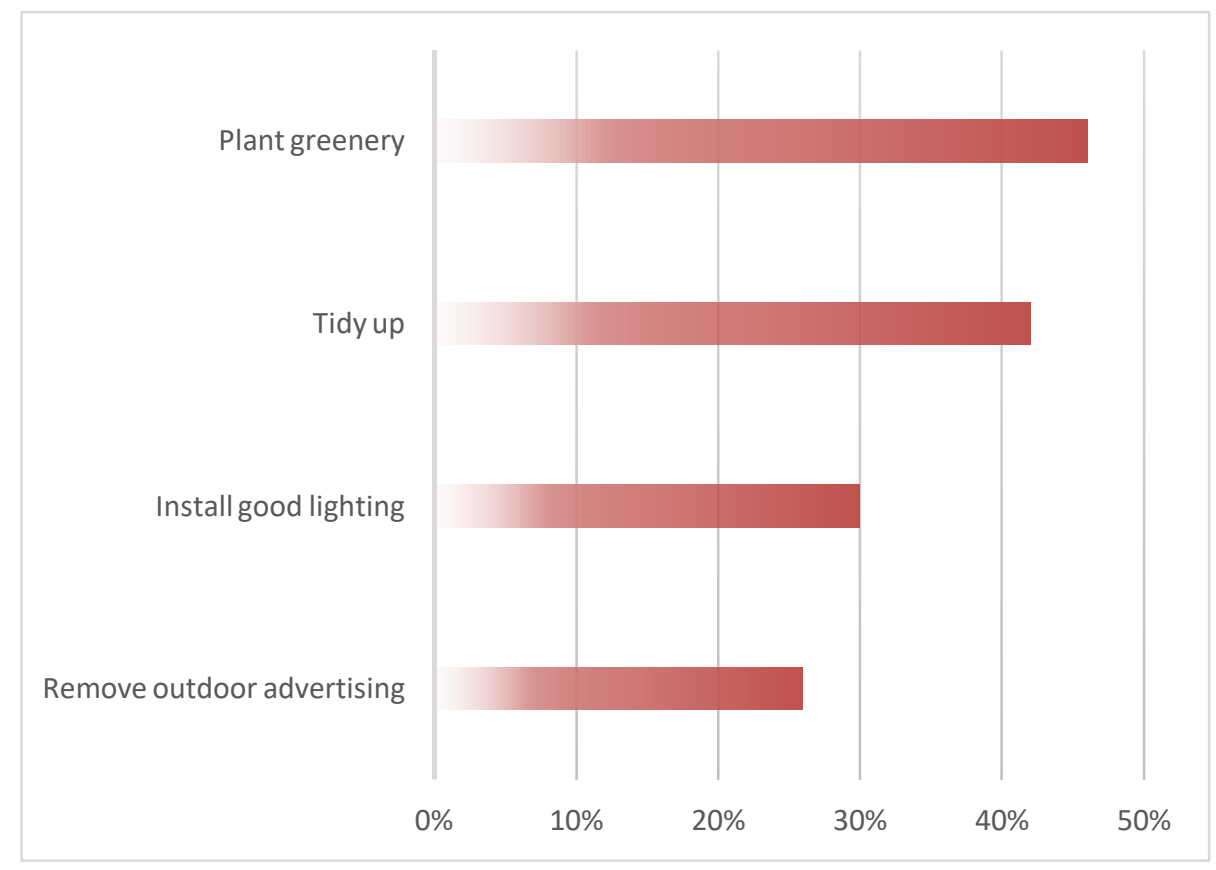

Fig. 1. The main changes that the respondent would like to make to the appearance of Perm

\subsection{The results of the main study}

The results of the study were supposed to show the difference in the perception of the city of Perm by students of different specialties, namely between technical and humanitarian areas. The selected group of respondents consisted of students in three areas: "architecture", "management", "electric power and electrical engineering". This representative sample is a group of respondents whose survey will collect information.

The obtained results once again proved our assumptions, emphasizing the difference between students receiving different specialties. A group of students studying in the field of "architecture" is experiencing in the first place artistic and aesthetic needs that exceed the group of students - "managers", and then a group of students - "electricians and electrical engineers".

The differences are significant ( $\mathrm{p}<0.05$ ). The Mann-Whitney U test was used. The data on the calculation of the correlation coefficients (Spearman's r-test) between creativity, tolerance, and artistic and aesthetic needs showed that there is a correlation (significance level $\mathrm{p}<0.05$ ) between the student's personal tolerance and personal creativity. These factors affect the features of aesthetic perception. Therefore, it is possible to conclude that students with high indicators of tolerance and creativity have clearly expressed needs of artistic and aesthetic perception, requiring more natural colors, as well as the variety of landscapes surrounding them. They are the main factors influencing the characteristics of the perception of the surrounding space, affecting the internal emotional well-being.

The second stage of the study was the use of the semantic differential developed by $\mathrm{C}$. Osgood. In the obtained semantic differential, 28 scales were used to realize our goals. This questionnaire was designed in such a way that we investigated emotional reactions and their relation to aesthetic assessments of architectural structures.

The results of an empirical study of students studying in different areas using semantic differentials are presented in a 10-point measurement. 
The Spearman r-test correlation between the profiles of the semantic differential for students of different faculties and different professional areas is high $(\mathrm{r}=0.91-0.97$ with $\mathrm{p}$ $<0.001)$. The obtained results showed that there are slight differences in the assessment of Perm city by students of different areas. Distinctive evaluations of the results were identified among "students-architects".

In the next phase of the study, students were encouraged to create a "dream city". The above data clearly show that the "dream city" is different from the realities that they face daily.

\begin{tabular}{|c|c|c|c|}
\hline Scale No. & Characteristic above axis OX & Scale No. & Characteristic above axis OX \\
\hline 1 & Rhythmic & 15 & Cozy \\
\hline 2 & Quick & 16 & Warm \\
\hline 3 & Exciting & 17 & Bright \\
\hline 4 & Lasting & 18 & Kind \\
\hline 5 & Beautiful & 19 & Filled \\
\hline 6 & Clean & 20 & Constant \\
\hline 7 & Tidy & 21 & Attracting \\
\hline 8 & Quiet & 22 & Developing \\
\hline 9 & Not crowded & 23 & Wide \\
\hline 10 & Active & 24 & Soft \\
\hline 11 & Calm & 25 & Blooming \\
\hline 12 & Light coloured & 26 & Strong \\
\hline 13 & Small & 27 & Miniature \\
\hline 14 & Old & & \\
\hline
\end{tabular}

Fig. 2. Correspondence of digital notation to semantic differential scales

Our research results presented in the table (with the correlation coefficients (Spearman's r-test) between the profiles of the semantic differential (SD)) prove the existence of differences. Respondents drew a clear line between assessments of the real city of Perm and "dream city".

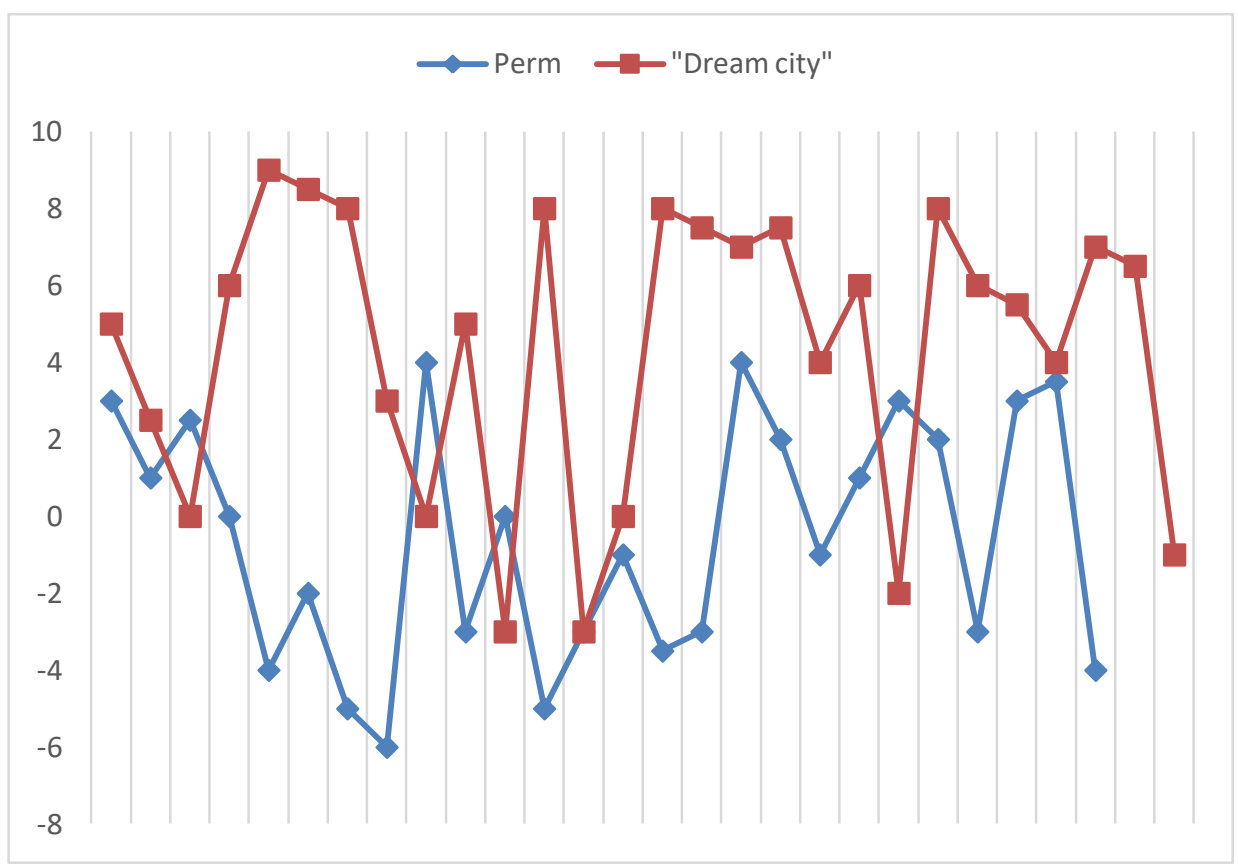

Fig. 3. Indicators of assessment of Perm and the "dream city" by students-architects 
We would like to emphasize that the research results show a significant difference between the characteristics that were given by students of different professional areas. Particularly obvious differences in the assessment of Perm and the "dream city" can be observed in the sample obtained among students - "architects", the differences in the groups of students studying in the area of "management" and students of the faculty of "electric power and electrical engineering" are not so pronounced. Perhaps this is due to the fact that the "student-architect", by the nature of his future activities, wants to build his own "dream city". The obtained results make it possible to get a different idea of Perm and the "dream city" (the obtained differences are significant by Spearman's r-criterion). After analyzing 10 of the 28 scales of semantic differential, the results obtained that characterize the features of the real and future cities: "dirty-clean", "messy-tidy", "cold-warm", "uncomfortable-cozy", "dull-bright", "dark- light", "evil-kind”, "noisy-quiet", "hard-soft”, "beautiful-ugly". After comparing the obtained data, we can conclude that Perm does not correspond to the "dream city".

The studies and the results obtained by the method of "factor analysis" of assessments among students of the city of Perm, which were obtained by means of the semantic differential "dream city", were able to determine three factors. [1].

The negative characteristic of the city of Perm was that this city is quite "ancient", unconsidered modern architecture can lead to the destruction of the image of Perm, causing negative emotions among local citizens.

The study of "crowding" (a feeling of lack of space) showed that only $9 \%$ of students have positive emotions about the number of people on the streets of Perm, $53 \%$ of respondents did not experience any emotions about the densely populated city. For $38 \%$ of the city's young population, "crowding" is a stress factor, which is why it very strongly affects the manifestation of aggressive behavior among young city residents.

\section{Research results}

1. As a result of the study, we identified the relationship between patience, tolerance, and the artistic and aesthetic needs of the individual;

2. We determined that respondents who have a higher tolerance assess the urban environment and problems in the urban environment from a positive point of view;

3. The indicators assessing the city of Perm by students of various specialties were almost the same;

4. Students - architects see a completely different dream city, although their colleagues studying in other faculties prefer to change something, but not dramatically;

5. Dirt, not tidy streets, advertising, violation of architectural styles cause negative emotions in a resident, even up to uncontrollable aggression.

\section{Conclusion}

The results of the study emphasize the importance of a "comfortable city" for a modern resident of a megalopolis, a city. The colors around us form our mood and psychological health. The environment surrounding us forms an individual attitude towards ourselves and our future. The environment surrounding us has the most direct impact on the psyche of the individual, forming his attitude towards everything that surrounds him. 


\section{References}

1. M.M. Andreeva, Psychological aspects of the visual perception of the urban environment. Soc. Psych.of the XXI Century: a collection of articles of the intern. congress. Yaroslavl (2018) http://www.psychosfera.ru/book/ book6/book68.html.

2. A. V. Anisimov, Architectural education of society . Cont. arch. and const. ed. as a fact. ensuring the quality of the living envir.: proc. of the gen. meet. of the RAACS. Voronezh: VGASU, pp. 268-271 (2005)

3. A.G. Asmolov, The word on tolerance. On the meanings of the concept of "tolerance”. Scie. j., No. 1, pp. 2-8 (2001)

4. O.A. Brown, On the question of factors determining the features of perception of the urban environment . Kemerovo State University, Access mode (2012) http://spf.kemsu.ru/portal/psy2002/2.8.shtml/.

5. V. V. Lazarev, Features of the perception of the urban environment . Continuous architectural and construction education as a factor in ensuring the quality of the living environment: proceedings of the general meeting of the RAACS, Voronezh: VGASU, pp. 20-25 (2005)

6. Modern studies of social problems (electronic journal), No. 109 92017)

7. H.E. Steinbach, Psychology of living space. SPb.: Rech, p. 239 (2004) 